\title{
Perdido nas trevas do iluminismo: El siglo de las luces, de Alejo Carpentier, como literatura memorialística
}

Christoph Schamm ${ }^{1}$

\begin{abstract}
Resumen: En 1962, Alejo Carpentier publica una novela considerablemente distinta de la mayoría de las obras de ficción que solemos asociar a la corriente de la nueva novela latino-americana: El siglo de las luces parece una novela histórica de carácter tradicional, bastante lejos de la estética de lo real maravilloso americano ideada por Carpentier pocos años antes. El presente artículo propone una lectura alternativa del texto, basándose en categorías de los estudos de memoria. Esta lectura desenmascara la ambivalencia de la novela, anulando así los mitos fundadores de la civilización europea y los sustituye por mitos fundadores específicamente latinoamericanos.
\end{abstract}

Palabras clave: Memoria, memoria cultural, novela histórica, mito fundador, realismo mágico

Resumo: Em 1962, Alejo Carpentier publica um romance que se diferencia consideravelmente da maioria das obras de ficção geralmente associadas à corrente da nueva novela latinoamericana: El siglo de las luces parece um romance histórico de cunho tradicional, bem distante da estética do real maravilhoso americano concebida por Carpentier poucos anos antes. O presente artigo propõe uma leitura alternativa do texto, baseando-se em categorias dos estudos memorialísticos. Desta maneira, revela a ambivalência do romance, que descarta os mitos fundadores da civilização europeia para substituí-los por mitos fundadores especificamente latino-americanos.

Palavras-chave: Memória, memória cultural, romance histórico, mito fundador, realismo mágico

Eles costumavam reunir-se diariamente em diferentes cafés de Paris, com a finalidade de discutir as novidades da literatura contemporânea e as ocorrências políticas na América Latina, naqueles anos tumultuados, por volta de 1930: o venezuelano Arturo Uslar Pietri,

\footnotetext{
1 Christoph Schamm é doutorado em Letras com ênfase em literaturas italiana e portuguesa (Universidade de Munique, Alemanha). Pesquisador visitante no Programa de Pós-Graduação em Letras da Universidade Federal do Rio Grande do Sul. Atividade docente na área de Literatura Comparada. Pesquisa sobre conceitos de poesia lírica, interferências entre texto e imagem na literatura e narrativas memorialísticas.
} 
o guatemalteco Miguel Ángel Asturias e o cubano Alejo Carpentier, todos eles olhando de longe para os seus países de origem que gemiam sob as ditaduras de caudilhos onipotentes. É assim que Uslar Pietri lembra, num livro publicado em 1986, as circunstâncias que dariam origem ao termo supostamente mais influente da história da literatura latino-americana do século passado: o Realismo Mágico. ${ }^{2}$ Embora o próprio Uslar chegasse a cunhar esse termo somente em 1948, num ensaio escrito durante o exílio norte-americano, ${ }^{3}$ na década de oitenta, já octogenário, ele avalia que aqueles distantes anos parisienses foram o início de tudo. A atmosfera febril da vanguarda surrealista teria estimulado os três jovens autores, encorajando-os a ousar experimentos literários ainda inéditos entre escritores latino-americanos. Também salienta, porém, que as relações amigáveis e artísticas com Breton e os seus seguidores, mantidas sobretudo por Asturias e Carpentier, não teriam sido o fator decisivo para esse desenvolvimento. O estímulo mais importante, conforme nos explica Uslar, foi o fracasso que os escritores experimentavam, cada vez que buscavam subordinar a sua visão da realidade latino-americana aos moldes incongruentes da literatura europeia, sem atingir resultados satisfatórios. Para o trio de escritores, o imaginário dos surrealistas, com relógios derretidos e gavetas encaixadas em corpos femininos, não era mais que um fenômeno decadente, a fase final de uma grande tradição esgotada. Eles, porém, se consideravam aptos a tirar vantagem desse delírio para renovar a literatura do seu próprio continente, pois sentiam-se representantes de um espaço cultural que, até esse momento, ainda não havia desenvolvido sua expressão adequada. Na retrospectiva de 1986, Uslar também enfatiza que o Realismo Mágico nunca pretendeu abrir mão da imitação da realidade para dar espaço a uma fantasia desenfreada e desarticulada. Ao invés disso, partia de uma noção de realidade mais larga e profunda que, conforme afirmavam os seus defensores, correspondia à complexa percepção dos latino-americanos.

Uslar Pietri, Asturias e Carpentier não tinham motivo para queixar-se: enquanto eles ainda viviam, o conceito de Realismo Mágico raramente foi colocado em questão pela crítica literária. Ao contrário, sua aceitação acabou tornando-se tão unânime que Emir Rodríguez Monegal, no prefácio de um estudo monográfico sobre esse fenômeno literário, repreende a devoção exagerada da academia à auto-interpretação dos escritores. ${ }^{4}$ Apesar de parecer irônico que logo Monegal, que realizou tantas entrevistas com literatos, se manifestasse dessa maneira, essa crítica provavelmente se justifica. De fato, a interpretação antropológica do Realismo Mágico, que o considera efeito imediato e inevitável da mestiçagem cultural no solo latino-americano, permanece em vigor até hoje. Num estudo introdutório à literatura hispanófona, publicado em 2003, essa estética ainda é declarada síntese de concepções mágicas provenientes da visão de mundo indígena com ideias realistas de origem europeia, como se isso fosse um fato incontestável. ${ }^{5}$ É bem possível, porém, que mestiçagem cultural e Realismo Mágico não sejam dois fenômenos tão firmemente interligados. Se realmente existisse a relação de causa e conseqüência, implicitamente afirmada por Alejo Carpentier no seu famoso ensaio sobre o real maravilhoso americano, por que, então, os autores latino-americanos precisariam de tantos anos para descobrir a expressão

\footnotetext{
2 Cf. Uslar Pietri 2004, p. 361/362.

3 Trata-se do livro intitulado Letras y hombres de Venezuela.

4 Estou me referindo ao volume $O$ Realismo Maravilhoso, da crítica brasileira Irlemar Chiampi, publicado em 1980. Cf. prefácio a Chiampi, 1980, p. 10-11.

5 Cf. Strosetzki, 2003. Neste estudo alemão, o Realismo Mágico é definido como "harmonização de concepções mágicas da visão de mundo indígena com idéias realistas de origem européia" ["Zusammenspiel magischer Anschauungsformen aus dem indianischen Weltbild mit realistischen Vorstellungen europäischer Provenienz"] (p. 141).
} 
originária de sua natureza? E por que logo um europeu como André Breton teria de assistir ao nascimento do Realismo Mágico na função de parteiro? Poder-se-ia responder a essas perguntas provocantes, dizendo que a literatura latino-americana, até meados do século passado, estava solidamente radicada em moldes ocidentais e não tinha condições de romper seus vínculos com eles. Mas esse argumento, embora pareça convincente, somente serviria para justificar o nascimento tardio do Realismo Mágico. Não poderia explicar, contudo, por que esse fenômeno literário, após duas décadas de prosperidade, acabou cedendo a outras tendências. Se realmente fosse consequência inseparável da mestiçagem cultural, deveria persistir enquanto ela persistisse.

Cien años de soledad, publicado somente em 1967, tornar-se-ia o texto do Realismo Mágico por excelência pelo mundo inteiro. Nos anos do famoso "boom", o nome dessa tendência se transformou num emblema que designava qualquer narrativa progressista escrita na América Latina. Sendo assim, é interessante observar que Alejo Carpentier, após ter influenciado o debate com o seu conceito do real maravilhoso, já procura outros caminhos nos anos cinquenta. Em 1948, ainda expressa a sua convicção de que "América está muy lejos de haber agotado su caudal de mitologías", uma vez que "[1] real maravilloso se encuentra a cada paso en las vidas de hombres que inscribieron fechas en la historia del continente y dejaron apellidos aún llevados: desde los buscadores de la fuente de la eterna juventud, de la áurea ciudad de Manoa, hasta ciertos rebeldes de la primera hora o ciertos héroes modernos de nuestras guerras de independencia [...]"7. E já que essa percepção da realidade especificamente latino-americana também se baseia na "presencia fáustica del indio y del negro", Carpentier adapta o hipotético ponto de vista de um escravo africano para narrar a história da Revolução Haitiana. No seu romance El reino de este mundo, de 1949, podemos escolher entre duas leituras alternativas, optando ou pelo entendimento realista ou pelo entendimento maravilhoso. Apesar da magia fazer parte da realidade fictícia do protagonista, a visão racionalista sempre continua transparecendo na narrativa. Dessa maneira, permanece indeterminado se o feiticeiro Mackandal, líder dos escravos revoltosos, é executado pelos colonizadores franceses ou não, pois o narrador nos proporciona a ideia de que ele consegue escapar, transformando-se em um pássaro; quem prefere, porém, pode optar pela versão de que os negros são chefiados por um morto a quem ainda consideram vivo. ${ }^{9}$

Carpentier abre caminho para o Realismo Mágico sem ele mesmo permanecer fiel a essa estética por muito tempo. A sua criação literária vivia procurando novos estímulos durante as décadas de quarenta e cinquenta, para ser submetida a contínuas transformações. Nas vésperas da Segunda Guerra Mundial, abandona Paris para passar vários anos em Havana, sua cidade de origem. Em 1945, transfere-se para Caracas, onde Uslar Pietri, seu companheiro dos tempos parisienses, acaba de ser nomeado Ministro do Interior. Permanece na Venezuela durante todo o regime de Fulgencio Batista em Cuba, para onde só retornará em 1959, após o ditador ser derrubado por Fidel Castro. Nesse período de violentas transformações políticas, Carpentier compõe o romance El siglo de las luces, que

6 Carpentier, 2003, p. 121.

7 Ibid., p. 120

8 Ibid., p. 121

9 No final do oitavo capítulo, que narra o martírio de Mackandal, encontra-se um bom exemplo de como o narrador privilegia a "percepção africana", sem completamente reprimir a "européia": "Aquella tarde los esclavos regresaron a sus haciendas riendo por todo el camino. Mackandal había cumplido su promesa, permaneciendo en el reino de este mundo. Una vez más eran burlados los blancos por los Altos Poderes de la Otra Orilla." (Carpentier, 1986, p. 41) 
só seria publicado em $1962 .{ }^{10}$ A obra é ambivalentemente relacionada com El reino de este mundo, texto redigido dez anos antes: por um lado, o narrador retorna ao mesmo contexto histórico, focalizando novamente as turbulências políticas no Caribe do fim do século XVIII. Até assistimos a uma breve visita dos protagonistas de El siglo de las luces a Porto Príncipe, cidade destroçada pelos insurgentes da revolta de 1791. Por outro lado, chama atenção Carpentier ter perdido completamente o interesse na estética do real maravilhoso, que formava a base da história do escravo Ti Noel. ${ }^{11}$ À primeira vista, El siglo de las luces parece um romance histórico que corresponde aos moldes mais tradicionais deste gênero, tendo um enredo entrelaçado de forma refinada numa sequência de fatos cuidadosamente investigados e apresentados de forma impecavelmente cronológica. No que diz respeito à linguagem, Carpentier também regressa aos padrões oitocentistas: o texto consiste em estruturas sintáticas extensas e elaboradas, contribuindo, dessa maneira, para nos transportar à virado do século XVIII para o XIX. ${ }^{12}$ Várias vezes, o narrador utiliza analogias ou símiles cujo entendimento exige um alto grau de cultura humanística dos seus leitores; como quando, por exemplo, compara um pescador que ergue uma lula gigantesca com o Perseu de Cellini. ${ }^{13}$ Poder-se-ia acrescentar que o romance, como as clássicas obras de ficção histórica costumam fazer, focaliza uma época especialmente significativa do passado: como todo o mundo sabe, é com a Revolução Francesa que os países latino-americanos iniciam sua transição da época colonial à independência. Em relação aos personagens, a narração não se concentra mais nos escravos negros, como em El reino de este mundo, mas assume deliberadamente o ponto de vista de crioulos brancos e europeus.

Trata-se, então, de um romance demasiado convencional e monótono? De forma alguma. Embora El siglo de las luces se diferencie superficialmente das grandes obras que geralmente associamos à literatura do boom, como por exemplo La casa verde, Rayuela ou Cien años de soledad, também participa da mesma procura febril de uma auto-imagem apropriada para o espaço latino-americano. Apesar do estilo oitocentista, aparentemente radicado nas convenções do realismo burguês, Carpentier ultrapassa em muito o esquema do romance histórico tradicional. $\mathrm{O}$ autor não pretende apresentar uma situação exemplar no desenvolvimento de um povo com a finalidade de definir seu caráter coletivo, com todos os seus supostos valores e virtudes. Nem persegue o objetivo de forjar a imagem ideal de uma nação que poderia servir para as futuras gerações nela se orientarem. Ao invés disso, ele se vale do modelo da ficção histórica como lente de aumento para expor uma problemática de suma importância, que parece afetar toda a comunidade cultural

10 Refiro-me, com todas as citações intercaladas no texto, à quinta edição do romance, publicada pela editora Seix Barral, Barcelona 2004.

11 Evidentemente, nem todos os intérpretes de Carpentier dividem a opinião de que o real maravilhoso é um conceito totalmente alheio à narrativa de El siglo de las luces. Emir Rodríguez Monegal, por exemplo, afirmou em 1971 que "Carpentier explotaría otras rutas de lo real maravilloso" nos seus romances após El reino de este mundo. Em El siglo de las luces, empreenderia "la recreación histórica de ese momento en que la Revolución Francesa llega a nuestra América, como adelantada de la Revolución de la Independencia” (Rodríguez Monegal, 1974, p. 97). Mas quem associaria esse romance ao real maravilhoso, se não fosse de Carpentier? Parece que alguns intérpretes hesitaram em aceitar o fato de o autor se desvincular dessa corrente, tão firmemente ligada ao seu nome.

12 Otto Maria Carpeaux, no seu prefácio à primeira edição portuguesa do romance, ressalta a maturidade estilística da apresentação do Caribe com palavras enfáticas: "[Carpentier] descreve com exatidão quase científica o mar e as ilhas, a fauna e a flora, os portos, os pescadores, os mercadores, os fazendeiros e os escravos - e tudo parece [...] um pesadelo febril num paraíso imaginário, uma viagem que nunca fizemos mas que nos parece o 'déjà vu' de um sonho." (Prefácio de Carpentier, 1976, p. 9)

13 Cf. Carpentier, 2004: "El gigante que, allá, al final del espigón, ofrecía un enorme calamar enlazado en lo alto, se transfiguraba en el Perseo de Cellini.” (p. 100) 
latino-americana. De forma sutil, consegue induzir-nos a uma leitura alegórica dos fatos subsequentes à Revolução Francesa ocorridos no Caribe. Como representante da nova ordem, o jacobino Victor Hugues chega às colônias para transformar os proprietários de terra e seus escravos em cidadãos livres e iguais, introduzindo os Direitos Humanos como fruto mais precioso do Século das Luzes. Mas, uma vez que os franceses desapropriados não querem abrir mão dos seus bens e os negros libertados não fazem questão de servir à República por vontade própria, precisa recorrer à guilhotina para impor sua autoridade. Após todo esse derramamento de sangue em Guadalupe, na França napoleônica, as leis revolucionárias acabam sendo descartadas, retomando-se a antiga ordem. Victor Hugues, entrementes nomeado para o cargo de governador da Guiana Francesa, torna-se perseguidor impiedoso de escravos revoltosos. Apesar de muitos sofrimentos e sacrifícios, a luta contra o autoritarismo colonial somente leva a um novo caudilhismo exacerbado. Esse círculo vicioso inescapável transforma-se, para Carpentier, na maldição da América Latina. ${ }^{14}$

Sabe-se, hoje em dia, que a narrativa pode ser uma tentativa de recuperar o passado. Afirma-se, até, que as obras de ficção são especialmente adequadas para desempenhar a função da memória coletiva, justamente porque não se entregam à ilusão historiográfica de que seja possível reconstruir uma única versão verdadeira do passado. Embora lembranças possam ser definidas como regressos mentais ao passado, é importante reconhecer que sempre permanecem firmemente ligadas às necessidades do presente: a princípio, qualquer evocação da memória é motivada pelo desejo de resolver problemas que se colocam na atualidade. Teóricos influentes como Jan Assmann salientaram o fato de que a memória cultural e a literatura ficcional, longe de serem a mesma coisa, devem ser consideradas dois fenômenos intimamente aparentados. ${ }^{15}$ Numa sociedade que se auto-define principalmente com base em textos escritos, esses fenômenos não existem um sem o outro. Apesar da literatura não ser o único conjunto simbólico que constitui a memória cultural, ela ocupa uma posição privilegiada dentro do leque das diversas formas possíveis: conforme uma convenção social, somente os textos ficcionais têm o direito de mesclar fatos reais e imaginários, constituíndo, dessa maneira, narrações totalmente coerentes e plenas de sentido. É nessa combinação lógica que os dados históricos, enriquecidos pelo imaginário poético, assumem significado e se tornam compreensíveis para a comunidade. Sendo assim, a literatura diferencia-se de outras formas da memória coletiva baseadas em narrações, pelo específico cruzamento da fronteira entre o real e o imaginário, definido por Wolfgang Iser, em um dos seus últimos estudos de maior fôlego, como ato de fingir. ${ }^{16}$ Embora a

14 Já no fim da década de sessenta, Luis Harss reconhece que o objetivo de El siglo de las luces consiste em "obtener una vasta síntesis de la experiencia americana". (Harss, 1973, p. 76) Nesse contexto, faz sentido ressaltar que Carpentier não apresenta a era da independência como "hora zero" da história latino-americana. Ao invés disso, até estende a retrospectiva para antes da Conquista, dedicando um capítulo a um relato das lutas indígenas antes da chegada dos espanhóis. (Cf. p. 283-286) Como Claudius Armbruster já demostrou em 1982, o escritor cubano radica o Caribe na memória coletiva como espaço de turbulências e mestiçagens perpétuas. (Cf. Armbruster, 1982, p. 206-209)

15 Conforme Assmann, a memória constrói o passado, mesclando fatos históricos e fictícios: "passado que é fixado e internalizado como história fundadora é mito, totalmente independente do fato de ser fictício ou factual." ["Vergangenheit, die zur fundierenden Geschichte verfestigt und verinnerlicht wird, ist Mythos, völlig unabhängig davon, ob sie fiktiv oder faktisch ist."] (Assmann, 2007, p. 76)

16 Iser, 1996, p. 15: "Na conversão da realidade da vida real repetida em signo doutra coisa, a transgressão de límites manifesta-se como uma forma de irrealização; na conversão do imaginário, que perde seu caráter difuso em favor de uma determinação, sucede uma realização (ein Realwerden) do imaginário." ["In der Überführung wiederholter lebensweltlicher Realität zum Zeichen für anderes manifestiert sich die Grenzüberschreitung als eine Form der Irrealisierung; in der Überführung des Imaginären als eines Diffusen in bestimmte Vorstellungen geschieht ein Realwerden des Imaginären.” (Iser ,1993, p. 22)] 
quantidade de fatos históricos seja limitada, a ficção nunca se esgota, porque cada época reivindica sua própria narração do passado.

Conforme Assmann, a literatura desempenha a função de atualizar e estabilizar os mitos de fundação que garantem a identidade coletiva de uma comunidade cultural. ${ }^{17}$ Em sua obra seminal de 1992, Das kulturelle Gedächtnis [A memória cultural], o teórico desenvolve suas hipóteses sobre como a memória cultural é gerada e preservada, refletindo a respeito dos povos antigos do Oriente Próximo. Não deixa dúvidas, porém, de que considera esse reservatório de mitos um universal antropológico. Sobretudo esse último aspecto provoca fortes objeções que, com certeza, não podem ser ignoradas por um intérprete da obra de Carpentier: os críticos de Assmann argumentam que a modernidade se distingue de todas as épocas anteriores justamente pelo fato da coesão da memória cultural ter-se perdido. ${ }^{18} \mathrm{O}$ discurso pluralizado do século $\mathrm{XX}$ não perseguiria mais o objetivo de estabilizar mitos unitários para comunidades amplas, mas, ao contrário, reduziria a memória geral a fragmentos sempre menores. Colocou-se em questão, por isso, se a narrativa contemporânea ainda poderia contribuir para a preservação de lembranças partilhadas por toda uma coletividade, como foi sugerido implicitamente por Assmann. Ao invés disso, a literatura dos dois séculos passados seria o lugar onde se delineia claramente a crise da memória cultural, talvez com maior evidência nos escritos dos poetas vanguardistas. ${ }^{19}$ Apesar dessas objeções parecerem bem-justificadas, não se pode partir do princípio que a ruína da memória cultural na literatura europeia se manifeste de igual maneira na narrativa latino-americana. Faria sentido, com certeza, afirmar que o teor da modernidade ocidental se manifesta em El siglo de las luces, à medida que Carpentier desvaloriza um grande mito ocidental nesse romance: demostra que a Revolução Francesa, fracassando tragicamente na região caribenha, não conseguiu tornar todos os homens livres e iguais. No entretanto, o significado do texto não parece esgotar-se com o desencantamento face a esse momento histórico, geralmente comemorado como aurora do republicanismo pela burguesia iluminista. Tratando o eco da revolução no Caribe como tema especificamente latino-americano, Carpentier contribui para uma auto-definição do seu espaço cultural, tanto almejada pelas nuevas novelas do boom.

Contudo, é preciso observar o texto com um olhar mais acurado para entender como o autor consegue transformar o romance histórico num diagnóstico atemporal e desiludido. A pergunta mais comum quando se trata de romances históricos refere-se ao limite entre o real e o imaginário. A princípio, poder-se-ia estranhar esse fato, pois a síntese dos dois fenômenos existe em qualquer obra de ficção, até nas mais fantásticas ou documentais. Mas parece que a fronteira entre o real e o imaginário nos romances históricos é menos clara ou especialmente significativa; de qualquer maneira, é o aspecto em que a atenção dos intérpretes costuma concentrar-se. Em geral, os autores escolhem personagens imaginárias

$17 \mathrm{O}$ conceito de mito, na forma como é utilizado neste artigo, corresponde à definição de Jan Assmann: "Mito é uma história que contamos a nós mesmos, a fim de nos orientar em relação a nossa própria natureza e ao mundo, uma verdade de ordem superior que não apenas está correta, mas, mais do que isso, também possui caráter normativo e poder formativo." ["Mythos ist eine Geschichte, die man sich erzählt, um sich über sich selbst und die Welt zu orientieren, eine Wahrheit höherer Ordnung, die nicht einfach nur stimmt, sondern darüber hinaus auch noch normative Ansprüche stellt und formative Kraft besitzt.'] (Assmann, 2007, p. 76)

18 Cf. Oesterle, 2009, p. 11-12.

19 Isso vale, pelo menos, para as correntes da vanguarda européia. Já nos movimentos latino-americanos como, por exemplo, no Primeiro Modernismo brasileiro, percebe-se a aspiração de formar uma memória coletiva, em vez de somente aniquilá-la: enquanto os futuristas italianos exigem a destruição de bibliotecas e museus, Oswald de Andrade tenta estabelecer um vínculo entre a sociedade atual e suas supostas raízes indígenas. 
como protagonistas e personagens históricas para papéis secundários. Esse procedimento explica-se, obviamente, pelo desejo de acionar os protagonistas conforme as necessidades do enredo, o que dificilmente poderia se fazer com uma personagem histórica cuja biografia foi detalhadamente reconstruída. Carpentier, porém, se vale do fato de que se sabe pouco sobre a vida de Victor Hugues, alcunhado de "Robespierre das Antilhas". O personagem central de El siglo de las luces, nativo de Marselha, foi criado em circunstâncias humildes e transferiu-se, mais tarde, para o Haiti, colônia francesa nesta época, para viver como comerciante em Porto Príncipe. Voltou para a França depois da insurreção dos escravos em 1791, logo associando-se aos jacobinos e assumindo cargos administrativos na Paris revolucionária. Em 1794, Robespierre encarrega-o de instalar a nova lei na Ilha de Guadalupe, provavelmente por causa de sua experiência anterior no Mar do Caribe. Para cumprir essa missão, Hugues primeiro vê-se obrigado a combater o exército inglês, que se havia aproveitado do caos parisiense para ocupar a colônia francesa. Consegue expulsar o inimigo da ilha, o que lhe confere uma reputação heróica da qual ainda pode usufruir após a chegada de Bonaparte ao poder, quando é nomeado governador da Guiana francesa. Apesar dessa posição importante, desconhecemos as circunstâncias precisas dos seus últimos anos de vida. Sendo assim, Hugues parece uma personagem que emerge da escuridão para, mais tarde, mergulhar nela novamente. Carpentier tira vantagem dessas lacunas para completálas com ocorrências imaginárias, estabelecendo relações de causa e conseqüência entre os fatos históricos e os inventados por ele mesmo. O seu procedimento pode ser citado como caso exemplar do cruzamento de fronteiras mencionado anteriormente.

A narração de Carpentier introduz o personagem de Hugues no final do seu primeiro período caribenho, atuando como comerciante e envolvido em negócios de contrabando. O momento em que Victor aparece em cena pela primeira vez é fulminante: batendo com violência na porta de uma mansão em Havana, invade o mundo recluso de Carlos e Sofía, jovens irmãos que vivem completamente recolhidos após a morte do seu pai. Junto com o primo Esteban, aplicam o capital herdado em tratados filosóficos, aparelhos óticos, astrolábios e qualquer outra novidade científica gerada pelo espírito iluminista da época. Não é difícil reconhecer o caráter alegórico desse momento-chave que desencadeará todo o enredo posterior: após a morte da antiga ordem colonial, encarnada pelo pai de Carlos e Sofía, súdito fiel da coroa espanhola, entram em cena homens livres e auto-conscientes. A revolução, porém, cristalizada na personagem do maçom Victor Hugues, não tarda em irromper nesse mundo lúdico e idílico, como se fosse um fantasma evocado pelos inocentes jogos dos adolescentes. Uma vez conquistada a amizade e a confiança dos jovens, Victor reorganiza a vida dos mesmos: expulsa o administrador do negócio paterno que se aproveitava da ingenuidade de Carlos para embolsar os lucros, cura Esteban dos seus torturantes ataques asmáticos e torna-se amante de Sofía. Desde o início, porém, também revela-se o caráter contraditório do aventureiro que, embora viva pregando a abolição da propriedade particular, enriquece através do contrabando de seda francesa para as colônias espanholas.

Não somente Sofía é seduzida por Victor. Sobretudo Esteban, o primo do casal de irmãos cubanos, é fortemente contagiado pelo pensamento revolucionário e maçônico do francês e resolve acompanhá-lo ao Haiti. Ironicamente, Victor, o livre-pensador, será a primeira vítima das insurreções subsequentes às turbulências na França: quando ele e Esteban chegam a Porto Príncipe, somente encontram os destroços fumegantes do seu armazém. Pela primeira vez, Esteban vira testemunha da onda de violência que, a partir desse momento, continuará abalando o Caribe. Aqui confirma-se o pressentimento que 


\section{Conexão Letras}

sempre lhe assaltava quando contemplava seu quadro favorito na casa dos primos em Havana, uma obra intitulada Explosão em uma catedral, atribuída, no romance, a um mestre napolitano desconhecido. Numa entrevista, Carpentier revelou que o seu texto, na verdade, se referia a uma pintura de Monsù Desiderio, um artista barroco em que os surrealistas viram prefigurada a sua estética. ${ }^{20}$ De qualquer maneira, Esteban reconhece o quadro intuitivamente como agouro de um futuro sinistro, pois cada vez que Sofía o interrogava sobre o seu estranho interesse nessa representação de um desastre, respondia: "Es para irme acostumbrando." (p. 22) Mas no momento em que, junto com Victor, foge dos negros enfurecidos do Haiti, embarcando no último navio para a França, ainda não tem consciência disso.

Somente depois da chegada em Paris, Esteban começa a desencantar-se de seu ídolo, percebendo que Victor não costuma basear suas amizades em convicções comuns, mas, bem ao contrário, suas convicções na amizade das pessoas que lhe parecem úteis. No passado, havia-se associado com Jean-Baptiste Willermoz, influente maçom e fabricante de tecidos, porque lucrava com as mercadorias dele no Caribe. Agora, despojado do seu negócio, não vê mais serventia nesse contato e procura outras alianças. ${ }^{21}$ Enquanto Esteban ainda frequenta os círculos da franco-maçonaria, nos quais foi introduzido pelo próprio Victor, esse já se compromete com os jacobinos de Robespierre. Um dia, explica ao seu amigo que os ritos místicos e os símbolos egípcios das sociedades secretas são uma perda de tempo e que, quem tem intenção de fazer política séria deve distanciar-se deles. Esteban, embora surpreso com a guinada ideológica de Victor, acaba aceitando sua proposta de assumir uma modesta função a serviço da Revolução: o jovem cubano passa a traduzir panfletos políticos para o espanhol, uma vez que os jacobinos pretendem divulgar o seu ideário do outro lado dos Pireneus. Passa uns meses monótonos em Baiona, antes de ser convocado por Victor para acompanhá-lo como secretário na expedição para Guadalupe, onde a ordem feudal deve ser substituída pela republicana. Inicia, nesse momento, a aventura que tornaria Hugues um personagem de importância histórica.

Mais uma vez, é preciso recorrer às reflexões perspicazes de Uslar Pietri. Num ensaio dos anos oitenta, diferente daquele anteriormente citado, o autor venezuelano manifestou as suas dúvidas a respeito da instalação do constitucionalismo europeu em países latino-americanos no início do século XIX. As tentativas de transformar as colônias em democracias, certamente, foram motivadas por nobres intenções; entretanto, não levaram a condições favoráveis porque, na maioria dos casos, ainda não existia o fundamento social e intelectual que esse sistema político pressupunha:

[...] la América Latina, cuando queda abandonada a su suerte por primera vez, es decir, en la Independencia, y cuando intenta adoptar instituciones venidas de afuera, una república a la francesa o a la americana, un parlamentarismo a la inglesa, un Derecho Civil europeo, en el momento en que intenta eso y que eso fracasa, la América Latina regresa a formas políticas que no tenían nada que ver con la contemporaneidad europea y occidental. ${ }^{22}$

É óbvio que ainda não chegamos ao momento de transição decisivo comentado por Uslar, quando Victor Hugues, em 1794, manda erguer a guilhotina na praça central de

20 Cf. Wakefield, 2004, p. 162.

21 Parece importante ressaltar, neste contexto, que Willermoz, assim como Hugues, é uma personagem histórica. A conexão entre eles, porém, foi provavelmente estabelecido por Carpentier.

22 Uslar Pietri, 2002, p. 94. 
Pointe-à-Pitre, capital de Guadalupe. Mas, de certa forma, esse acontecimento e os fatos sucessivos antecipam o que se repitiria tantas vezes nos países latino-americanos: depois da ambição de se criar uma sociedade ideal ter fracassado, forma-se, de acordo com Uslar, "la única creación política original que ha dado la América Latina que es el caudillismo rural." Hugues persiste no objetivo de instaurar em sua ilha uma república conforme os princípios jacobinos, superior àquela que, quando de sua partida, já começava a decair na França - pois lá, aparentemente, o fundamento social e intelectual necessário para a ordem democrática também não existia. Ele está consciente de que os colonos franceses, na maioria, rejeitam a nova ordem representada por ele. Já durante a viagem marítima, percebendo a repulsão de Esteban contra a guilhotina, explica ao amigo que a liberdade não se baseia menos nesse aparelho do que na imprensa. ${ }^{23}$ Uma vez reconquistada Guadalupe, logo comprova que aprendeu perfeitamente os métodos do líder jacobino Maximilien Robespierre: 865 dos soldados britânicos presos se revelam colonos franceses que preferiam pagar impostos à coroa inglesa a abrir mão de seus escravos. Sendo a guilhotina demasiado lenta para tal quantidade de cabeças, o comissário da Convenção Nacional manda fuzilar os cidadãos relutantes.

Mas Victor Hugues ainda teria bastantes oportunidades de utilizar a sua guilhotina. Na prática, as condições de vida dos negros de Guadalupe não se modificam significativamente. Apesar de serem declarados cidadãos livres e iguais aos colonos franceses, são obrigados a continuar o seu serviço nas plantações de açúcar, já que Hugues decreta o trabalho obrigatório e não tem outro uso para pessoas sem escolaridade. Quem se revolta contra a sua autoridade, seja branco ou negro, é imediatamente decapitado. Nessa altura do enredo, Esteban perde definitivamente a confiança no amigo e resolve abandonar Guadalupe assim que possível. No final, escapa para Cuba, passando pela Guiana francesa, onde vê os jacobinos responsáveis pelo terror vermelho, agora prisioneiros na colônia penal, junto com padres da Igreja Católica que foram desterrados por eles. Antes disso, porém, ainda se torna testemunha de como Hugues toma medidas escandalosas para melhorar o balancete financeiro de sua administração em Guadalupe: consciente de que muitos escravos fugitivos de todo o Caribe tentam alcançar a ilha, manda seus corsários interceptarem suas embarcações. Evitando que cheguem ao território francês, pode vender os negros clandestinamente aos ingleses.

Esteban, porém não precisa mais dessa última decepção com a política colonial da França revolucionária para entender que as luzes do pensamento iluminista não se adaptarão facilmente à realidade latino-americana. Por outro lado, também dá-se conta de que as transformações na Europa desencadearam um processo cujo termo é absolutamente imprevisível. Arauto de um desenvolvimento ainda por vir, Hugues derrubara os pilares da antiga ordem sem saber como substituí-los. Logo que retorna à casa dos primos, em Havana, Esteban detém-se diante do quadro, cujo enigma conseguiu finalmente decifrar: "Si la catedral era la Época, una formidable explosión, en efecto, había derribado sus muros principales, enterrando bajo un salud de escombros a los mismos que acaso construyeran la máquina infernal." (p. 295) Parece que Carpentier, desistindo completamente do imaginário do real maravilhoso, recorre a um jogo com vários espelhos para representar o mundo latino-americano adequadamente: assim, compreende as ocorrências inéditas na última década do século XVIII como primeira rotação do círculo

23 “"¡Conque esto también viajaba con nosotros!», exclamó Esteban. «Inevitablemente — dijo Víctor, regresando al camarote- Esto y la imprenta son las dos cosas más necesarias que llevamos a bordo, fuera de los cañones.»)" (p. 144) 


\section{Conexão Letras}

vicioso em que o continente permaneceria preso. O quadro barroco, mencionado repetidas vezes no decorrer da narração, serve de analogia para a situação inescapável de toda uma comunidade cultural, sem esgotar-se nessa função: além disso, constitui um reflexo do próprio romance, resumindo de forma concentrada o mito de fundação que se delineia como significado alegórico do texto inteiro. Manifesta-se, nessa interpretação diferenciada da repercussão da Revolução Francesa no Caribe, uma ambivalência que parece caracterizar a literatura do boom, ou seja, as nuevas novelas: por um lado, essas obras permanecem associadas à literatura moderna europeia, pois também continuam derrubando os mitos tradicionais do mundo ocidental. Por outro, aproveitam a crise da memória cultural subsequente à Segunda Guerra para finalmente criar as narrações que definiriam a identidade coletiva da América Latina. Apenas através desses novos mitos, por mais que tendam para a amargura e o fatalismo, se forma o perfil tão anelado pelo continente inteiro.

No quadro de Monsù Desiderio, a ideia da transformação interminável reflete-se na imagem de um "terremoto estático, tumulto silencioso, ilustración del fin de los tiempos, puesto ahí, al alcance de las manos, en terrible suspenso." (p. 22) O funesto mestre barroco produz esse efeito pintando os escombros das colunas em queda com tanta nitidez como se estivessem congelados no ar. Quem realmente estivesse diante deles, dificilmente poderia ter uma percepção semelhante, pois o cenário apresentado persistiria apenas por uma fração de segundos. Alejo Carpentier, porém, consegue proporcionar-nos a mesma visão hiper-realista, produzindo-a através da narração extremamente detalhada de El siglo de las luces.

\section{Referências}

ARMBRUSTER, Claudius. Das Werk Alejo Carpentiers. Chronik der ,Wunderbaren Wirklichkeit. Frankfurt am Main: Vervuert, 1982.

ASSMANN, Jan. Das kulturelle Gedächtnis. Schrift, Erinnerung und politische Identität in frühen Hochkulturen. $6^{\mathrm{a}}$ ed. Munique: Beck, 2007.

CARPENTIER, Alejo. El reino de este mundo. $3^{\mathrm{a}}$ ed. Barcelona: Biblioteca de Bolsillo, 1986.

El siglo de las luces. 5a ed. Barcelona: Seix Barral, 2004.

. O século das luzes. Trad. Stella Leonardos. Rio de Janeiro: Labor do Brasil. 1976.

De lo real maravilloso americano. In: Ensayos selectos. Buenos Aires: Corregidor, 2003. p. 101-122.

CHIAMPI, Irlemar. O realismo maravilhoso. Forma e ideologia no romance hispanoamericano. São Paulo: Perspectiva, 1980.

HARSS, Luis. Los nuestros. $5^{\text {a }}$ ed. Buenos Aires: Sudamericana, 1973.

ISER, Wolfgang. Das Fiktive und das Imaginäre. Perspektiven literarischer Anthropologie. Frankfurt am Main: Suhrkamp, 1993.

O Fictício e o Imaginário. Perspectivas de uma antropologia literária. Trad. Johannes Kretschmer. Rio de Janeiro: EdUERJ, 1996.

OESTERLE, Günter. Kontroversen und Perspektiven in der Erinnerungs- und Gedächtnisforschung. In: Judith Klinger e Gerhard Wolf (Org.). Gedächtnis und kultureller Wandel. Erinnerndes Schreiben - Perspektiven und Kontroversen. Tübingen: Niemeyer, 2009. p. 9-18.

RODRÍGUEZ MONEGAL, Emir. Lo real y lo maravilloso en El reino de este mundo. In: __. Narradores de esta América. Buenos Aires: Alfa Argentina, 1974. v. II, p. 64-98. 
STROSETZKI, Christoph. Einführung in die spanische und lateinamerikanische Literaturwissenschaft. Berlim: Erich Schmidt, 2003.

USLAR PIETRI, Arturo. ¿Existe América Latina? In: . Ensayos sobre el Nuevo Mundo. Antología de textos políticos. Madrid: Tecnos, 2002. p. 85-102. . Realismo mágico. In: John Skirius (Org.). El ensayo hispanoamericano del siglo $\overline{X X} .5^{\text {a }}$ ed. México: Fondo de Cultura Económica, 2004. p. 361-366.

WAKEFIELD, Steve. Carpentier's Baroque Fiction: returning Medusa's gaze. Woodbridge: Tamesis, 2004. 